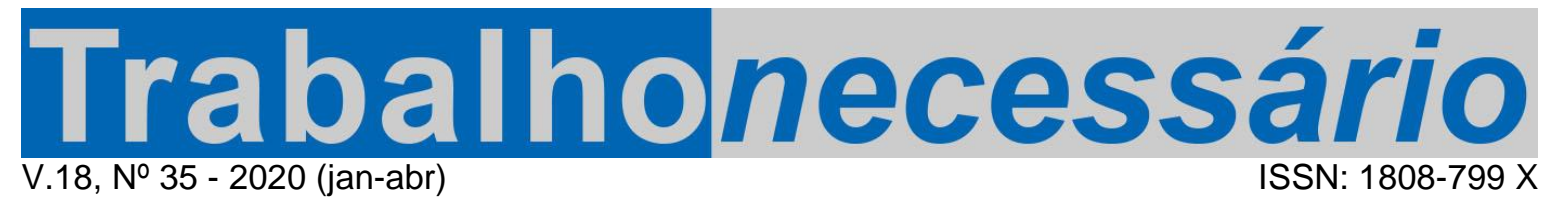

DOI: https://doi.org/10.22409/tn.v18i35.40491

\title{
NOTAS PARA O ESTUDO DO TRABALHO INDUSTRIAL URBANO: 0 PRINCÍPIO EDUCATIVO DA "ESCOLA PARA TODOS” A PARTIR DA MODERNIDADE ${ }^{1}$
}

Dalton José Alves²

\begin{abstract}
Resumo
O tema deste artigo resulta de pesquisas sobre o princípio educativo da escola pública, localizado no trabalho urbano industrial a partir da Modernidade. A pesquisa evidenciou que o trabalho na indústria e na cidade revolucionou os modos de vida. O desenvolvimento das potencialidades humanas passou a depender dos progressos da indústria. Disto surgirá uma nova pedagogia da hegemonia da classe proprietária, antes feudal, agora capitalista, para a consolidação do seu projeto de sociedade. A proposição da escola para todos surge neste contexto. Analisa-se as contradições em relação à escola para os trabalhadores.

Palavras-chave: Trabalho e Educação; História - Capitalismo; Escola Pública; Princípio Educativo; Dualidade Educacional;

NOTAS PARA EL ESTUDIO SOBRE EL TRABAJO INDUSTRIAL URBANO: O PRINCIPIO EDUCATIVO DE LA “ESCUELA PARA TODOS” A PARTIR DE LA MODERNIDAD.
\end{abstract}

\section{Resumen}

El presente trabajo es el resultado de investigaciones sobre el principio educativo de la escuela pública, a partir del trabajo urbano industrial en la Modernidad. El estúdio evidencia que el trabajo en la indústria y en la ciudad revolucionó los modos de vida. El desarrollo de las potencias humanas pasó a depender de los progresos industriales. Con ello, surgió una nueva pedagógia hegemónica de la clase proprietária, antes feudal, ahora capitalista que busca su proyecto de sociedad. La escuela para todos surge como propuesta ante este panorama, queriendo analizar con ello las contradicciones en relación a la escuela para los trabajadores.

Palabras clave: Trabajo y Educación; Historia- Capitalismo; Escuela Pública; Principio Educativo; Dualidad Educativa

\section{NOTES FOR THE STUDY OF INDUSTRIAL WORK URBAN: THE EDUCATIONAL PRINCIPLE OF “SCHOOL FOR EVERYONE” FROM MODERNITY.}

\section{Abstract}

The theme of this article results from research on the educational principles of public schools stemming from modernity: the urban industrial work. Research has shown that work in industries and in the city has revolutionized lifestyles. The development of human potential came to depend on the progress of industry. This will result in the emergency of a new pedagogy of hegemony of a previously feudal, now capitalist,

1 Artigo recebido em 01/07/2019. Primeira Avaliação em 01/09/2019. Segunda Avaliação em 05/11/2019. Aprovado em 21/11/2019. Publicado em 23/01/2020.

2 Doutor em Educação na Área de Filosofia e História da Educação. Professor Associado II da Universidade Federal do Estado do Rio de Janeiro (UNIRIO). E-mail: dalton.alves@unirio.br. ORCID: https://orcid.org/0000-0002-2036-4069. 
proprietary class for the consolidation of their project of society. The proposition of a "school for all" emerges in this context and contradictions regarding a school for the working class are analyzed.

Keywords: Work and Education; History- Capitalism; Public School; Educational Principle; Educational Duality.

\section{Introdução}

Neste texto, tem-se por objetivo geral abordar o conceito e o fato do trabalho, entendidos como atividades teórico-práticas e da sua relação, na história, com a origem da educação e o surgimento da escola. Trata-se de como a organização do processo de trabalho nos primórdios da humanidade exigiu a necessidade da educação como meio de passar para as novas gerações os conhecimentos desenvolvidos pelas anteriores, tendo em vista a perpetuação da espécie humana; bem como dá-se um enfoque específico ao contexto histórico, o qual determinou a emergência da Scholé (lugar do ócio), na antiguidade grega e romana, como nova modalidade particular de educação, restrita a pequenos grupos, destinada às classes economicamente dominantes da sociedade, diferente da educação própria das demais classes. Este modelo se estenderá ao conjunto da sociedade como a principal forma de educação para todos, a partir da Modernidade, o qual permanece até hoje como a forma predominante de educação da maioria.

Entender as razões que deram origem à escola é fundamental para compreender qual é o papel da escolarização na formação dos seres humanos na atualidade, uma vez que a escola se tornou a modalidade de educação para todos. Deste modo, é possível delimitar, mais precisamente, quais os limites e a importância da educação escolar no tempo presente, sobretudo da escola pública, que, em linhas gerais, é a responsável também pela educação da classe trabalhadora, da maioria dos cidadãos.

O conhecimento da história do ser e estar humano no mundo passa pela compreensão do papel do trabalho e da educação no processo de humanização. Pelo trabalho, a humanidade produz a sua própria existência e pela educação, garante a continuidade e o aperfeiçoamento desta produção. Ao existirem, os seres humanos precisaram trabalhar e se educar de alguma forma, necessariamente. Todavia, se a educação é tão antiga quanto o homem e, desde sempre, foi uma exigência social e para o trabalho, para todos os membros da sociedade, a educação escolar, no entanto, nem sempre se submeteu a estas exigências. 
A educação escolar passa a ser uma exigência social para todos somente a partir da época Moderna e, sobretudo, após a primeira Revolução Industrial, que deslocou a economia da agricultura para a indústria, a política do campo para a cidade e o processo produtivo do trabalhador para as máquinas.

O trabalho produtivo material, pelo qual os seres humanos criam coisas úteis para a sua sobrevivência, tais como, alimentos, vestuários, abrigos, transportes etc., foi desde sempre um princípio educativo da educação em geral dos homens. Em outros termos, a organização do trabalho, nos primórdios da humanidade, exigiu a necessidade da educação como meio de passar para as novas gerações os conhecimentos desenvolvidos pelas gerações anteriores, tendo em vista a perpetuação da espécie humana. O trabalho e a educação, portanto, são tão antigos quanto os seres humanos. Desde o surgimento da espécie humana, impôs-se a necessidade de se dedicar ao trabalho, de agir sobre a natureza para transformá-la e de criar coisas úteis para o consumo e o bem-estar humanos, bem como teve a premência de se educar, de passar para as novas gerações o domínio dos conhecimentos sobre o trabalho e de outras atividades, descobertas e criações humanas adquiridos em cada momento da história.

Compreende-se o "trabalho como princípio educativo", conforme a definição de Ciavatta (2009), que traduz este conceito de Marx e Gramsci, segundo a qual,

[...] No caso do trabalho como princípio educativo, a afirmação remete à relação entre o trabalho e a educação no qual se afirma o caráter formativo do trabalho e da educação como ação humanizadora por meio do desenvolvimento de todas as potencialidades do ser humano (CIAVATTA, 2009, p. 408).

Nesta acepção, o trabalho como princípio educativo dos seres humanos, acima comentado, irá se traduzir também, no Período Moderno, em princípio educativo da escola pública para todos, proposição defendida pela Burguesia na sua fase revolucionária. E este era o trabalho industrial.

O trabalho na indústria e na cidade, à medida que produz mercadorias para os capitalistas, com base nas novas tecnologias criadas por engenheiros e cientistas de todos os tipos e áreas, revoluciona o modo de vida dos grupos humanos da Modernidade, inicialmente na Europa, depois em todo o mundo, até a contemporaneidade. 
O desenvolvimento das potencialidades humanas, desde então, passou a depender dos progressos da indústria. Gramsci (2001) percebeu bem este fato ao analisar o papel da escola primária e notar a sua relação com o trabalho na indústria. Segundo ele,

[...] a lei civil e estatal organiza os homens do modo historicamente mais adequado a dominar as leis da natureza, isto é, a tornar mais fácil o seu trabalho, que é a forma própria através da qual o homem participa ativamente na vida da natureza, visando a transformá-la e socializá-la cada vez mais profunda e extensamente. Pode-se dizer, por isso, que o princípio educativo no qual se baseavam as escolas primárias era o conceito de trabalho, que não pode se realizar em todo seu poder de expansão e de produtividade sem um conhecimento exato e realista das leis naturais e sem uma ordem legal que regule organicamente a vida dos homens entre si [...] O conceito e o fato do trabalho (da atividade teórico-prática) é o princípio educativo imanente à escola primária, já que a ordem social e estatal (direitos e deveres) é introduzida e identificada na ordem natural pelo trabalho. (GRAMSCI, 2001, p. 43).

Assim é, porque, à medida em que a criança é introduzida na apropriação do desenvolvimento histórico da humanidade é que ela irá melhor se situar no mundo atual, enquanto indivíduo e ser social, bem como é devido a isto que poderá intervir, ativamente, na construção do futuro por sua ação no presente. Esta ação se traduzirá em sua maior capacidade de intervenção pelo trabalho na realidade material, física, natural e pela política na sua melhor intervenção na realidade humana e social, retomadas a um nível mais elevado, para transformá-las.

Deve-se a isto a razão de estarem os estudos veiculados pela escola centrados nas áreas das ciências físicas e naturais, nas áreas dos estudos histórico-sociais e da linguagem. O estudo das ciências, por exemplo, ensina à criança sobre as leis naturais, "objetivas e rebeldes", que independem da vontade humana e não podem ser suprimidas, em relação às quais apenas é possível conhecer e se adaptar. Tratamse de elementos e fenômenos naturais em que não há possibilidade de evitar ou controlar (GRAMSCI, 2001, p. 42). Tais como: a morte; não é possível evitá-la, mas pela medicina, a química e outras ciências, pode-se adiá-la, bem como curar várias doenças e enfermidades que tornariam a vida mais dolorosa e sofrida. Há também a meteorologia, que permite ao homem prever chuvas, furacões, secas, etc. Entretanto, não se pode evitá-los; mas é possível se preparar para enfrentar esses fenômenos da natureza, e, assim, sofrer menos. 
$\mathrm{Na}$ escola, aprende-se, também, sobre as leis civis e estatais que regem a organização e a vida em sociedade nos tempos atuais, porém, ao contrário das leis naturais, estas podem ser modificadas, pois trata-se de produtos humanos. São leis estabelecidas pelos próprios homens tendo em vista o seu desenvolvimento coletivo, por isto, por se tratarem de leis construídas pelos homens, podem por eles serem desconstruídas e modificadas. A escola visa, em linhas gerais, proporcionar aos homens o domínio mais adequado possível dos conhecimentos necessários para atuarem sobre as leis da natureza e da vida social de forma a facilitar a sua vida e tornar mais fácil o seu trabalho.

Evidencia-se, assim, que, a partir da Revolução Industrial do século XVIII, o trabalho urbano produtivo material com base na indústria tornou-se, paulatinamente, o princípio educativo, agora centrado na escola, para todos os membros da sociedade. Todos precisam dominar esses conhecimentos. Seja para aplicá-los na produção, no trabalho industrial, mas também para compreender os fundamentos científicos que sustentam a vida nessa nova sociedade baseada na produção industrial.

Esta é uma exigência posta para todas as classes sociais. Na sociedade urbana industrial, a situação da educação se apresenta de modo substancialmente diverso dos períodos anteriores, antigo e medieval, uma vez que o modo de vida atual das classes proprietárias e não-proprietárias assenta-se nos mesmos fundamentos, científicos e tecnológicos. Tanto é assim que o currículo das escolas é formalmente o mesmo para todas as escolas, de todos os níveis sociais, de acordo com a política de estado de educação em vigor.

Nas demais partes deste texto visa-se esmiuçar esta realidade de modo a mostrar, tanto quanto possível, como está estruturada a escola na sociedade atual, a partir da identificação dos seus fundamentos históricos, conceituais e sociais e das suas contradições.

\section{Gênese histórica do processo educativo baseado na escola: origens e finalidades}

Cumpre agora destacar brevemente qual foi o processo histórico que deu origem à escola e com quais finalidades ela foi criada no mundo antigo, em especial no mundo grego e romano. Inicialmente, pode-se dizer que a escola surge como uma modalidade específica de educação diferenciada da educação em geral pela qual se 
educavam as gerações anteriores. Outra característica, tratava-se de uma educação à qual só tinham acesso as classes nobres, aristocráticas e ricas. Estavam impedidos de frequentarem a escola: as mulheres, os escravos e os pobres, ou seja, a maioria da sociedade.

A escola surge, assim, como Scholé (lugar do ócio), mas não era um lugar de descanso ou de lazer, ao contrário, era o lugar para onde eram enviados aqueles que não precisavam trabalhar para viver, ou seja, os filhos dos proprietários. Surge e se consolida como resultado da divisão da sociedade em classes sociais, a classe dos proprietários e dos não-proprietários. Nasce com a transformação da propriedade coletiva dos meios de produção fundamentais, como a terra, em propriedade privada.

$\mathrm{Na}$ Scholé, ensinavam-se os conhecimentos e as técnicas necessários para dirigirem os trabalhos da mente, os quais exigiam esforço mental e intelectual. Não exerciam atividades manuais, consideradas indignas do homem livre, uma vez que estas eram próprias de escravos ou serviçais. As demais crianças, filhas dos nãoproprietários, estavam impedidas de frequentarem a Scholé, restrita aos nobres e aristocratas, mas também passavam por um processo de educação pelo qual aprendiam e dominavam os conhecimentos e técnicas necessários para dirigirem os trabalhos das mãos, os quais exigiam esforço físico e manual para o trabalho produtivo que deveriam exercer a serviço dos nobres e proprietários. (ZANELLA, 2003, p. 142).

A origem da propriedade privada que mudou radicalmente, pela raiz, a forma de vida das pessoas e dos povos para sempre, até os dias de hoje, teve início quando na história, além dos bens de produção privados, os meios de produção também passaram a ser privados. Passaram a pertencer apenas a uma família ou a um grupo restrito, deixando o restante da comunidade sem tais meios de sobrevivência. Disto irá resultar, aos poucos, a noção de "propriedade privada", particular, dos principais meios de produção da existência humana. E, muito rapidamente, as terras e os animais, que antes eram de todos, passaram a ser a propriedade particular de apenas alguns e a tribo, ao invés de trabalhar e ver os produtos do seu trabalho gerarem recursos para todos, passou a trabalhar e gerar recursos apenas para alguns poucos que se apoderaram da propriedade, antes coletiva e agora privada.

Segundo Engels,

Ao dividir-se a produção nos dois ramos principais - agricultura e ofícios manuais - surgiu a produção diretamente para a troca, a 
produção mercantil, e com ela o comércio, não só no interior e nas fronteiras da tribo como também por mar [...] A diferença entre ricos e pobres veio somar-se à diferença entre homens livres e escravos. A nova divisão do trabalho acarretou uma nova divisão da sociedade em classes. A diferença de riqueza entre os diversos chefes de família destruiu as antigas comunidades domésticas comunistas, em toda parte onde estas ainda subsistiam; acabou-se o trabalho comum da terra por conta daquelas comunidades. A terra cultivada foi distribuída entre as famílias particulares, a princípio por tempo limitado, depois para sempre; a transição à propriedade privada completa foi-se realizando aos poucos [...] A família individual começou a transformarse na unidade econômica da sociedade. (ENGELS, 2018, p. 200).

Os proprietários passaram a dominar a comunidade e, por conseguinte, 0 excedente de produção e passaram também a se sentirem no direito de não mais precisarem trabalhar na terra para o próprio sustento, obrigando toda a comunidade, depois de subjugada, a trabalhar para a sua própria subsistência e para sustentar os novos donos da terra. Se antes todos viviam do trabalho de todos, a partir deste momento "alguns passaram a poder viver do trabalho dos outros" (SAVIANI, 1995, 2ª . parte: "Origem e finalidade da escola"). Surge, a partir daí, o trabalho como exploração e não mais como meio próprio de vida e de subsistência. E a maior exploração de todas que foi o trabalho forçado, trabalho escravo, conhecido como Modo de Produção Escravista (NETTO e BRAZ, 2010, p. 65).

A escravidão, a princípio restrita aos prisioneiros de guerra, mas que
se desenvolve depois e abrange os membros da própria tribo e até da
própria gens; a degeneração da velha guerra entre as tribos na busca
sistemática, por terra e por mar, de gado, escravos e bens que podiam
ser capturados, ação que chegou a ser uma fonte regular de
enriquecimento. Resumindo: a riqueza passa a ser valorizada e
respeitada como um bem supremo, e as antigas instituições da gens
são pervertidas para se justificar a aquisição de riquezas pelo roubo e
pela violência. (ENGELS, 2018, p.131).

Ocorre assim, segundo Engels (2018, p.131), a legitimação histórica e social da propriedade privada, "antes tão pouco estimada", consagrada e santificada como o "objetivo mais elevado da comunidade humana", juntamente com a perpetuação da "nascente divisão da sociedade em classes" e do "direito de a classe possuidora explorar a não possuidora e o domínio da primeira sobre a segunda". Nestas condições, os proprietários passaram a ter mais tempo livre para se dedicarem a outras coisas, vez que estavam livres do trabalho produtivo, agora realizado por outros seres humanos escravizados. 
É neste contexto que teve origem a escola, como Scholé, uma modalidade restrita de educação, destinada apenas para aqueles que viviam do trabalho de outros homens, pois, a maioria continuava a se educar como sempre fez, no próprio trabalho e na vida. A escola nasce no mundo antigo, grego e romano, com esta marca congênita baseada na divisão entre trabalho intelectual e trabalho manual, resultante da divisão de classe da sociedade entre proprietários e não-proprietários, fruto do surgimento da propriedade privada dos meios de produção.

Isto perdurou até o fim da Idade Média, sofrendo mudanças durante as Revoluções Burguesas do Período Moderno, quando se levanta a bandeira e se efetiva a proposta da universalização da escolarização para todos da sociedade. Todavia, para a classe trabalhadora, em essência, as coisas não mudaram tanto assim. Não se modificaram, pois alterou-se a forma, mas não a lógica de organização e funcionamento da sociedade, uma vez que não se transformou, substancialmente, o regime de propriedade. Prevaleceu, portanto, o regime da propriedade privada dos meios de produção em detrimento do regime da propriedade coletiva, o que trouxe consequências também para o tipo de escola pública destinada aos trabalhadores, que irá resultar desse processo.

\section{Sobre o trabalho industrial como o princípio educativo da universalização da escola para todos: avanços e contradições}

Entre os séculos XVI e XIX, principalmente após a Revolução Industrial do século XVIII, intensifica-se a necessidade de capacitar técnica e cientificamente a mão-de-obra que deveria realizar os trabalhos na indústria, porque as máquinas tinham engastadas em seus mecanismos os fundamentos do conhecimento científico, sobretudo da física e da matemática, e como estes não eram passíveis de serem desenvolvidos espontaneamente, precisavam ser apreendidos de forma sistemática. A exigência de democratizar o acesso aos conhecimentos intelectuais e teóricos, inclusive para os trabalhadores, surge aos poucos, levando o sistema burguês de produção (capitalista) a colocar a necessidade da escolarização dessa mão-de-obra para atender aos seus objetivos na produção, a qual se tornou um imperativo conforme avançava o desenvolvimento da indústria, cada vez mais impulsionada pelos progressos científicos e tecnológicos das forças-produtivas a serviço da produção industrial e da acumulação ampliada do capital. 
A Scholé, que antes era uma modalidade restrita de educação, apenas para os nobres e aristocratas, generaliza-se e torna-se, com o passar do tempo, a modalidade principal de educação de toda a sociedade, consubstanciada na bandeira empunhada pela burguesia, em sua fase revolucionária da "luta pela escola pública para todos".

Segundo Saviani $(1994,1995,2007)$, é nesse período que a escola se tornará uma necessidade geral, convertendo-se na modalidade principal de educação. surgimento da indústria, no século XVIII, a expulsão dos camponeses de suas terras, o crescimento das cidades, a vida urbana, a invenção da imprensa, a Reforma Protestante, dentre outros fatores, são algumas das razões de as pessoas precisarem dominar os códigos escritos e os saberes científicos desenvolvidos pela escola.

Após a Revolução Francesa e a instituição da República como forma de governo, centrada na observância da Lei escrita (Constituição), no direito positivo, nos contratos de trabalho e do casamento civil etc., evidenciou-se o problema do analfabetismo. Como cobrar a observância da Lei de quem não sabe ler e escrever?

[...] a sociedade contratual, baseada nas relações formais, centrada na cidade e na indústria, vai trazer consigo a exigência de generalização da escola. A produção centrada na cidade e na indústria implica que o conhecimento, a ciência que é uma potência espiritual, se converta, através da indústria, em potência material [...]. Se se trata de uma sociedade baseada na cidade e na indústria, se a cidade é algo construído, artificial, não mais algo natural, isto vai implicar que esta sociedade organizada à base do direito positivo também vai trazer consigo a necessidade de generalização da escrita [...]. Na Época Moderna, a incorporação da ciência ao processo produtivo envolve a exigência da disseminação dos códigos formais, do código da escrita. O direito positivo é um direito registrado por escrito, muito diferente do direito natural que é espontâneo, transmitido pelos costumes. O domínio da escrita se converte, assim, numa necessidade generalizada. [...]. Quanto mais avança o processo urbano-industrial, mais se desloca a exigência da expansão escolar. Por aí é possível compreender exatamente por que esta sociedade moderna e burguesa levanta a bandeira da escolarização universal, gratuita, obrigatória e leiga. A escolaridade básica deve ser estendida a todos. (SAVIANI, 1994, p. 05).

E mais ainda: o domínio dos códigos escritos e a importância da alfabetização ligam-se à nova relação que se estabelecerá entre ciência e técnica, em que a ciência pura tornar-se-á ciência aplicada à produção - tecnologia - e colocará a exigência de um domínio teórico, por mínimo que seja, dos fundamentos científicos dos instrumentos e técnicas necessários à indústria. $\mathrm{E}$, uma vez que eram os trabalhadores quem deveriam operar tais maquinários, era preciso dar a eles o 
domínio do saber científico engendrado nas técnicas e máquinas da indústria. É assim que irá surgir, como uma necessidade objetiva, o problema do acesso dos trabalhadores à Scholé, local por excelência do desenvolvimento e acesso aos conhecimentos científicos e teóricos.

A mudança principal realizada pela Revolução Industrial foi a substituição da mão-de-obra humana pela máquina no processo produtivo. Se antes, na manufatura, o homem era a força produtiva central, se era ele (o trabalhador) quem agia sobre a matéria para transformá-la em algo útil para o consumo humano, agora, na indústria, transferiu-se para as máquinas as atividades manuais. Esta é a grande revolução industrial operada a partir de então, e que colocou a máquina no centro do processo produtivo, deslocando o homem (o trabalhador), transformando-o num "adendo" da máquina, que está ali apenas para garantir que esta continue funcionando bem e de modo eficiente. Não é mais ele (o trabalhador) quem age sobre a matéria para transformá-la, o trabalhador não é mais o produtor direto, e sim, é a máquina que agora ocupa esta função. De produtor, o trabalhador foi reduzido a "servo" da máquina.

Além disso, a produção mecanizada é muito mais eficiente e uniforme do que o corpo humano. Por esta razão é que a substituição do homem pela máquina apresenta inegáveis vantagens para o capital, tanto na redução dos custos, como na redução do tempo de produção, com a qual o trabalhador manual não pode competir. Daí o porquê de o modo de produção anterior, baseado na manufatura, ter sido abandonado e superado pela produção industrial (maquinofatura), devido às vantagens objetivas deste novo modo de produção.

A indústria, tendo o seu processo produtivo centrado nas máquinas e não mais no trabalho humano direto, e sendo a máquina resultado de conhecimentos científicos da física, da mecânica, da matemática etc., passou a exigir, gradativamente, dos trabalhadores que as operavam algum nível de conhecimento científico-tecnológico, mas, estes conhecimentos teóricos não podiam ser desenvolvidos somente pela observação empírica, como antes, no trabalho manual. Precisavam de estudos mais complexos, só acessíveis e veiculados por instituições específicas, conhecidas como escolas ou academias. Neste contexto, é que a escola, aos poucos, irá se converter na principal forma de educação da maioria, em substituição à educação empírica e espontânea das épocas anteriores, nas quais a educação escolar estava restrita aos 
nobres e aristocratas. Atualmente, a educação escolar é tão natural e óbvia que muitos nem têm a noção de que nem sempre ela foi uma necessidade para todos da sociedade. (SAVIANI, 1995, 3ª parte: "Quando a escola se generaliza").

Todavia, para os trabalhadores estas mudanças não foram tão vantajosas conforme o prometido. Segundo Saviani (1995), estas mudanças poderiam ser vantajosas ao liberar os trabalhadores das atividades manuais pesadas, sobrando mais tempo livre para se dedicarem a outras coisas. Mas, na prática, isto acaba não ocorrendo porque a máquina não é dos trabalhadores, elas têm um dono (o capitalista) e estão a serviço deste. Por isto, a Revolução Industrial irá trazer muitos prejuízos para o trabalhador, principalmente o desemprego, vez que uma máquina poderia exercer a função de muitos operários manuais ao mesmo tempo, necessitando-se apenas de alguns poucos homens para o manuseio dessas máquinas. (SAVIANI, 1995, 4a . parte: "A escola e a Primeira Revolução Industrial").

Outra desvantagem para a classe trabalhadora foi em relação ao acesso à Scholé. A escola, ao surgir no cenário das Revoluções Burguesas como uma necessidade objetiva e erigindo-se na forma principal de educação para todos, para desenvolver o domínio do saber ler, escrever e contar, bem como dos conhecimentos científicos e teóricos, surgiu como uma grande conquista, o que de fato foi, mas não sem contradições e limites.

A defesa da educação escolar para todos, inclusive para a classe trabalhadora, coloca para a burguesia o problema de em que medida isto deveria ser feito? Até onde poderia ir o domínio, por parte dos trabalhadores, dos conhecimentos veiculados pela escola? Note-se que, do ponto de vista histórico, da história da educação da mão de obra à serviço da classe dos proprietários, é a primeira vez que a classe dirigente irá se ver diante do problema de que não bastava mais uma formação apenas manual, empírica, do ser que trabalha, como forma de o explorar para a geração de riquezas e subsistência da classe senhora do trabalho.

A solução será organizar um tipo de escola para a classe trabalhadora, por quem não é trabalhador, mas dele precisa. Assim essa escola é planejada e oferecida aos trabalhadores, em sua forma e conteúdo, de acordo com as necessidades dos seus idealizadores. (ALVES, 2018, p. 184).

Por esta razão é que a burguesia, ao criar a escola pública no processo de consolidação do novo modo de produção (capitalista), não considerou a participação 
dos trabalhadores na elaboração do modelo de educação escolar que melhor convinha aos próprios trabalhadores. Apesar de se proclamar o princípio de "uma escola pública, laica, gratuita, para todos", ignorou-se, em vários aspectos, as necessidades específicas dos trabalhadores, os quais foram excluídos deste processo e não foram ouvidos sobre a educação que melhor atenderia às suas necessidades.

Daí entende-se o porquê de se criar um modelo de escola "para" e não "com" a classe trabalhadora. Este modelo foi pensado a partir dos interesses dos capitalistas, para atender às suas necessidades de acumulação ampliada do capital, pouco interessando a formação dos trabalhadores, a seu serviço, naquilo que não atendesse a estas necessidades. Tal modelo de escolarização não considerava, em última instância, favorecer o desenvolvimento mais amplo das potencialidades humanas e profissionais dos indivíduos da classe trabalhadora para além dos interesses imediatos da economia capitalista. Do que se depreende qual é a concepção do ser que trabalha subjacente ao projeto de escola pública burguesa forjado neste contexto, qual seja, concebe-se o indivíduo que trabalha apenas como mão-de-obra útil ao capital, em detrimento de ele ser também um ser humano e tudo o que isto implica do ponto de vista da sua educação e emancipação. Assim como nos modos de produção anteriores, feudal e escravista, concebia-se a mão-de-obra útil, o ser que trabalha, como uma classe de seres tipicamente humanos, porém, desprovidos da sua humanidade.

O objetivo da burguesia foi, de fato, promover a escolarização dos trabalhadores, porém, no dizer de Gramsci, como seres "[...] aridamente instruídos para um ofício, sem ideias gerais, sem cultura geral, sem alma, mas só com o olho certeiro e a mão firme" (GRAMSCI apud MONASTA, 2010, p. 67), e não uma escola propriamente de formação humana em sentido omnilateral.

Tratar-se-á de uma escola pública, de direito, mas, de fato, estará restrita a pequenos grupos. A Modernidade capitalista e burguesa, já na primeira Revolução Industrial, lança as bases do que seria uma nova Scholé, criando duas modalidades distintas de educação escolar, uma não tendo ligação com a outra. Tratou-se de uma escola de tipo dualista, isto é, uma escola de excelência intelectual, de formação geral, para o trabalho complexo, reservada aos ricos e outra escola de qualidade inferior, minimalista, de formação prática, para o trabalho simples, destinada aos pobres, para a classe trabalhadora. 
É neste contexto que surge, então, a tese da educação escolar em "doses homeopáticas" para os trabalhadores como a solução mais adequada aos interesses em jogo, visando adaptar todos à nova ordem social nascente, à ordem burguesa $\mathrm{e}$ capitalista, a qual irá determinar o sentido real do lema e da defesa de uma escola pública para todos, proposição defendida pela burguesia. Tratar-se-á de uma escola pública, mas não igual e nem do mesmo tipo para todos (ZANELLA, 2003, p. 142170).

Segundo Ana Margarida Campello,

a escola não é única, nem unificadora, mas constituída pela unidade contraditória de duas redes de escolarização: a rede de formação dos trabalhadores manuais e a rede de formação dos trabalhadores intelectuais [...] Essa diferenciação se concretizou pela oferta de escolas de formação profissional e escolas de formação acadêmica para 0 atendimento de populações com diferentes origens e destinação social [...] A escola de formação das elites e a escola de formação do proletariado [...] A educação profissional destinada àqueles que estão sendo preparados para executar o processo de trabalho, e a educação científico-acadêmica destinada àqueles que vão conceber e controlar este processo" (CAMPELLO, 2009, p.136).

A dualidade educacional caracteriza-se, em resumo, pela oferta de um tipo de escolarização de excelência para as classes ricas e dirigentes, com enfoque no desenvolvimento intelectual destinado à preparação para o ingresso no ensino superior e para assumir, posteriormente, os cargos de direção e comando no mercado de trabalho e na sociedade. E outro tipo de escolarização minimalista, destinada às classes pobres e subalternas, para o ingresso imediato no mercado de trabalho, num emprego qualquer, de baixa remuneração e que pouco exige do seu desenvolvimento intelectual para atuar na produção, geralmente em trabalhos manuais.

Em outros termos, a dualidade é inerente à escola na sociedade capitalista. Não se trata de um fenômeno acidental e nem de um equívoco, e sim, configura uma dualidade estrutural, essencial, própria do sistema liberal-burguês. É por isto que apesar dos ganhos que representou para a classe trabalhadora a possibilidade do acesso à educação escolar, em relação à sua situação anterior, isto não se alterou tanto conforme prometido, uma vez que o real fundamento da escola está na dualidade educacional.

Percebe-se que já na origem a educação prevista para o trabalhador está condicionada às necessidades da produção capitalista. Desde o 
início a educação requerida, pensada e oferecida à classe trabalhadora é concebida apenas como a formação de um "meio de produção" para o mercado de trabalho capitalista e não como uma educação para a formação humana, do ser humano que há no trabalhador, ao contrário, trata-se de um modelo de educação que visa a formação do trabalhador no ser humano, daí desenvolver-se mais os aspectos operacionais na sua formação em detrimento dos aspectos humanistas e de formação geral (ALVES, 2018, p. 166).

Enfim, as correlações de forças não permitiram à classe trabalhadora uma escola melhor, que lhe proporcionasse cultura geral e formação omnilateral. Resultou que a burguesia inaugura, de fato, uma nova modalidade de educação ao universalizar a escola como a forma principal de educação, a escola pública para todos, mas também cria uma diferenciação na escolarização destinada aos capitalistas e aquela que seria destinada aos trabalhadores.

Tal como a Scholé na antiguidade e no Período Medieval, a educação dos trabalhadores, a partir da Modernidade, não será a mesma da classe dirigente, capitalista, os novos "proprietários" no poder. A escola para os novos proprietários irá continuar a sua antiga função de desenvolver os aspectos intelectuais e a capacidade de "mando", para a qual estão destinados apenas aqueles que irão ocupar as funções de direção geral da sociedade e/ou do processo produtivo.

A escola pública popular, por outro lado, consolida-se como uma forma limitada de educação para os subalternos, com vistas a desenvolver, nestes, apenas os conhecimentos práticos e manuais e que pouco exijam da sua capacidade intelectual.

Nesta acepção, a qualidade da escola pública para os trabalhadores deve ser encarada sob outra ótica. A notória e muitas vezes alegada "má qualidade" da escola pública popular, realmente não é má, e sim, trata-se da qualidade requerida pelo sistema para a educação desta classe social. Segundo Gaudêncio Frigotto (2001),

\begin{abstract}
A desqualificação da escola, para a grande maioria que constitui a classe trabalhadora, não é uma questão conjuntural - algo, como insinua a tecnocracia, a ser redimido, recuperado pelos mecanismos técnicos (ou pela tecnologia educacional). Trata-se de uma desqualificação orgânica, uma "irracionalidade racional", uma "improdutividade produtiva", necessária à manutenção da divisão social do trabalho e, mais amplamente, à manutenção da sociedade de classes. (FRIGOTTO, 2001, p. 180).
\end{abstract}

Cabe destacar, neste contexto, um problema para os professores e aqueles que se identificam com a defesa do princípio da escola pública e de qualidade para 
todos, que, ao se confrontarem com esta realidade, isto pode configurar nesses profissionais e outras pessoas da sociedade civil uma série de dramas e levá-los a um sentimento de desânimo e de apatia ao saberem que a escola, em especial a escola pública, ao contrário do que se imagina e se espera, na realidade, foi criada para controlar e limitar tanto quanto possível o acesso dos trabalhadores ao conhecimento sistematizado, científico e aos instrumentos de produção do conhecimento teórico, não por alguma situação conjuntural, por ignorância ou equívoco dos governantes de plantão, mas que isto faz parte estrutural da própria concepção da escola pública popular.

Todavia, apesar desta situação adversa, não se deve perder de vista que a escola é muito importante para a classe trabalhadora. Qualquer ideia em contrário tende a condenar os trabalhadores a uma "miséria" cultural ainda maior e que lhes seria muito mais prejudicial, em última instância, negar o valor da educação escolar em sua vida. A questão da escola para os trabalhadores implica algumas contradições as quais, se consideradas, podem converter-se em ganhos para esta classe.

A este respeito pode-se destacar o que diz Saviani (1994):

Na medida em que o saber se generaliza e é apropriado por todos, então os trabalhadores passam a ser proprietários de meios de produção. Mas é da essência da sociedade capitalista que o trabalhador só detenha a força de trabalho. Aí está a contradição que se insere na essência do capitalismo: o trabalhador não pode ter meio de produção, não pode deter o saber, mas, sem o saber, ele também não pode produzir, porque para transformar a matéria precisa dominar algum tipo de saber. Sim, é preciso, mas "em doses homeopáticas", apenas aquele mínimo para poder operar a produção. É difícil fixar limite, daí por que a escola entra nesse processo contraditório: ela é reivindicada pelas massas trabalhadoras, mas as camadas dominantes relutam em expandi-la (SAVIANI, 1994, p. 09, grifos nossos)

Isto significa que, apesar dos limites do ensino escolar como veículo de transformação social, dado aos seus condicionantes políticos, econômicos e ideológicos, as contradições apontadas dão margem para ações rumo à constituição de uma escola emancipadora, porque, por exemplo, à medida em que se lute por melhores condições de trabalho dos profissionais da educação, dos professores e dos alunos que atuam na escola; à medida que se consiga melhorar a qualidade do ensino e da aprendizagem, com professores bem formados, escolas bem equipadas, novas didáticas e novas metodologias de ensino que despertem o interesse dos jovens pelo 
estudo etc.; enfim, ao melhorar a qualidade da escola pública, garante-se um melhor aproveitamento dos estudos por parte dos estudantes trabalhadores e, quiçá, para além dos limites desejados e impostos pelo capitalismo. Vez que "é difícil fixar este limite", então, um dos caminhos é forçar a escola a ultrapassá-lo.

\section{Legado e atualidade da proposição da escola como modelo de educação para todos no Brasil}

Tendo em vista a importância de garantir a qualidade da escola pública popular para a classe trabalhadora, pode-se situar os reflexos no Brasil das transformações ocorridas na Europa, no período em que se inicia a profissionalização do trabalho docente, consubstanciado na Constituição Federal de 1934.

Dentre as transformações econômicas, políticas e sociais ocorridas na Europa no período da Modernidade, após a Revolução Industrial e a Revolução Francesa, destaca-se, nesta parte, os seus desdobramentos no campo educacional, em relação à necessidade da valorização do trabalhador docente, os quais se fizeram sentir no Brasil com maior intensidade e força a partir da Constituição de 1934, que instituiu o princípio republicano da educação como direito de todos. Neste contexto, a partir de então, passa a ser considerado essencial o papel do professor.

Não restam dúvidas de que o principal patrimônio do Sistema Educacional Brasileiro é a capacidade docente, tanto intelectual, como também técnica ou profissional, para desenvolver projetos, pesquisas e oportunizar a todos os cidadãos o direito social à educação, previsto no artigo 6‥ da Constituição Federal vigente (OLIVEIRA e PIRES, 2014, p.75).

Colocar no centro do processo educativo escolar a relevância e a "essencialidade do trabalho dos professores", implica garantir a efetiva valorização dos profissionais de ensino.

A necessidade de valorização do trabalhador docente após 1930, coincide com o início da intensificação do processo de industrialização brasileira, a qual ganha força e avança a passos largos com Vargas. Pode-se associar isto à primeira Revolução Industrial europeia do século XVIII, podendo considerar a década de 1930, de certa forma, o princípio da "revolução industrial" nacional.

A Revolução Industrial europeia opera, como se sabe e já comentado neste trabalho, uma inversão no processo produtivo: se antes, na manufatura, o ser humano, 
a mão-de-obra humana, ocupava o centro do processo produtivo, pois era o ser humano quem, efetivamente, produzia com suas próprias mãos, e com auxílio de instrumentos, os produtos destinados à venda e ao consumo humano, com o surgimento das máquinas, estas passam a ocupar este lugar, deslocando os seres humanos (os trabalhadores) para a "periferia" do processo produtivo, transformandoos em um adendo das máquinas. Agora são as máquinas que produzem e a "mão-deobra" humana passa a ter apenas a função de "cuidar" do bom funcionamento das máquinas. O homem (o trabalhador) passa a ter a função acessória de ligar, desligar, limpar, consertar as máquinas. "De produtor, o operário é literalmente reduzido a servente de um mecanismo, com cuja força, regularidade e velocidade ele não pode competir" (SINGER, 1987, p. 17).

A questão dos professores, da docência e da escola ganha relevância neste contexto, pois, sendo as máquinas criadas a partir de conhecimentos científicos complexos e especializados, com base na física, química, engenharia, matemática etc., estas passaram a demandar operadores também especializados e que dominassem, minimamente, tais conhecimentos científicos, uns mais outros menos, dependendo da função que cada um ocupava no processo produtivo. Assim, a necessidade de trabalhadores que tivessem algum conhecimento científico e técnico aumentava, gradativamente, conforme avançava 0 desenvolvimento e a complexidade da produção industrial, uma vez que a formação espontânea, manual e intuitiva não dava mais conta de formar, adequadamente, para as novas funções requeridas pelo trabalho industrial.

A atividade científica que dará origem às máquinas, sendo ela própria uma atividade sistemática e sistematizada, não espontânea, irá requerer um estudo e aprendizado igualmente sistemáticos e sistematizados. Esta é uma das razões pelas quais se tornará imperiosa a necessidade do acesso à escola para os trabalhadores.

Daí a afirmação de Saviani (1995) de que "essa revolução industrial que colocou a máquina no centro do processo produtivo, teve uma correspondente revolução educacional que colocou a escola no centro do processo educativo" e com ela desponta o papel central dos professores na educação de todos da sociedade.

Porque é a partir do conceito de escola que a realidade educacional pode ser explicitada. O que quero dizer com isto, é que os professores, então, são os educadores por excelência da nossa época. E o habitat dessa atividade educacional são as escolas. E, portanto, o movimento 
dos professores, as condições de trabalho dos professores, os salários dos professores, estão diretamente ligados ao desenvolvimento ou não, à melhoria ou não, da educação da nossa época. (SAVIANI, 1995).

Por isto, pode-se entender porque o Estado brasileiro irá assumir e implementar a partir de 1930, a profissionalização do trabalho docente no país, vez que é também deste período o início ou a intensificação da industrialização nacional. $E$, assim como na Revolução Industrial europeia, coloca-se aqui, do mesmo modo, a necessidade da escolarização da mão-de-obra e, portanto, de profissionais da docência mais preparados para a função de escolarizá-la.

Apresenta-se, neste contexto no Brasil, na década de 1930, o trabalhador docente como o principal patrimônio do sistema educacional brasileiro e enfatiza-se a capacidade docente tanto intelectual como técnica e profissional. Disto resultará todo um "ordenamento jurídico brasileiro" com o objetivo de "garantir a valorização profissional do trabalho docente" (OLIVEIRA e PIRES, 2014, p. 75).

Porém, ao nível das políticas de Estado da Educação realmente efetivadas durante o século $X X$ e atualmente no século $X X I$, a situação dos professores sofre profundas mudanças no sentido contrário aos objetivos proclamados, de precarização do trabalho docente, sobretudo, a partir da década de 1970 e, depois, durante e após a década de 1990, quando são adotados os princípios neoliberais como política oficial de Estado no Brasil. A partir daí, será introduzido o trabalho precário com maior intensidade causando, consequentemente, uma reordenação nos sistemas educacionais, redefinindo o papel do Estado em relação às políticas sociais, dentre as quais a educação, introduzindo-se a lógica gerencial empresarial como a medida de eficiência e eficácia da escola.

Trata-se da mercantilização da educação e do trabalho docente, ou seja, considerar tudo como redutível à lógica de mercado, de compra e venda. Esta "nova organização laboral do ensino", do trabalho docente, é marcada por forte "ideologia de mercado", a qual compreende a função docente como uma mercadoria e não como um direito. A consequência imediata se fez sentir na forma de uma crescente desvalorização do papel social do professor e na flexibilização do trabalho docente que trouxe o efeito da queda da qualidade do ensino e, consequentemente, da aprendizagem. 
Curioso observar que isto ocorre num contexto em que a escola se generalizava para "todos" no Brasil; justamente aí cai a qualidade do ensino e da aprendizagem na escola pública. Quando o acesso ao saber elaborado, sistematizado, teórico e científico, é colocado acessível à grande massa, observa-se a queda da qualidade da escola pública de nível básico no país.

Considerando estas ideias, pode-se afirmar que essa nova organização laboral (neoliberal) tem contribuído para a desvalorização do papel social do professor, pela flexibilização do trabalho docente, com efeitos na atividade laboral e na qualidade do ensino. Situação que se agrava se situada com base no princípio do Estado Democrático de Direito, do qual o Estado brasileiro se diz signatário, e como tal deveria primar pela "proteção da dignidade da pessoa humana". No caso do trabalho docente, "este princípio basilar é estendido quando do ambiente de trabalho digno ao exercício pleno da profissão docente" (OLIVEIRA e PIRES, 2014, p. 76).

Formalmente, o corpo legislativo brasileiro é repleto de elementos que indicam a defesa de princípios de valorização dos profissionais do ensino e de compromissos com uma qualidade educacional elevada. Porém, qual é o grau de efetividade dessas leis no cenário atual brasileiro? O problema, neste caso, é evidenciar "o grau de comprometimento do Poder Público para com a efetivação dessas normas, visto que foram elaboradas com fincas no princípio da dignidade da pessoa humana, quando da sua extensão ao meio ambiente de trabalho docente" (OLIVEIRA e PIRES, 2014, p.76).

O que precisa ser evidenciado é que esta precarização do trabalho resulta, dentre outros fatores, do fato de a adoção das políticas neoliberais do estado-mínimo estarem em franca contradição com o princípio basilar do Estado Democrático de Direito.

Em relação à determinação constitucional que exige, do Estado, zelar e garantir a "valorização do trabalho docente", ao se assumir como política pública de Estado os princípios neoliberais do estado-mínimo, opera-se na realidade a "demissão" do Estado em relação às suas obrigações de garantir a eficácia das normas de valorização do trabalho docente. Essas leis e normas tendem a se tornarem "letra morta", inócuas, pois, o princípio basilar do Estado Democrático de Direito implica num alto grau de comprometimento do Poder Público para a efetivação das normas existentes (OLIVEIRA e PIRES, 2014, p. 76). Numa situação em que se adotam os 
princípios neoliberais do estado-mínimo não se pode mais contar com este comprometimento do Poder Público para a efetivação dessas normas.

É neste aspecto que o neoliberalismo entra em contradição com os princípios de um Estado Democrático de Direito. Dado que o segundo se caracteriza pela criação e a garantia de direitos e a efetivação das normas e o primeiro pela eliminação de direitos e a flexibilização das normas. A política do estado-mínimo prega a não intervenção do Estado na gerência da economia, devendo reduzir ao máximo a criação de leis que limitem e controlem a livre iniciativa do capital, flexibilizando a aplicação das leis existentes e aquelas a serem criadas. Pode-se concluir que sob a lógica do princípio do estado-mínimo é insustentável a manutenção de uma sociedade "democrática" e de "direitos". Isto porque a adoção de um destes torna impossível a sustentação do outro. São mutuamente excludentes. As políticas públicas assentadas nos princípios de um Estado Democrático de Direito são incompatíveis com a adoção do neoliberalismo, pois, ao contrário do apregoado por este, aquele exige um Estado forte e presente no cuidado para a efetivação das normas que ele mesmo cria, "elaboradas com fincas no princípio da dignidade da pessoa humana" (OLIVEIRA e PIRES, 2014).

O caminho, neste caso, para se conquistar a dignidade do exercício do trabalho docente, passa pela luta contra a adoção dos princípios neoliberais para que se tenha um comprometimento do Estado com a efetivação das normas, para que sejam aplicadas em defesa dos direitos do profissional docente.

\section{Considerações finais}

As considerações feitas neste texto sobre trabalho e educação, o surgimento e universalização da escola como modelo predominante de educação para todos, bem como o papel central do trabalho urbano industrial como o princípio educativo por excelência do processo de escolarização da sociedade, visaram evidenciar a importância, não sem contradições, da educação escolar em nossa época, sobretudo, da educação para os trabalhadores.

Os avanços das forças produtivas, a partir do século XVI e, principalmente, do século XVIII, na Europa, provocaram uma inevitável crise das relações de produção pré-existentes exigindo a sua transformação e adequação às novas condições materiais e sociais constituintes a partir de então. 
Dentre o estabelecimento das novas relações de produção, tem a exigência de que seja dado aos trabalhadores o acesso aos conhecimentos científicos, ao menos aos seus fundamentos, e o domínio básico dos instrumentos de produção do saber sistemático e teórico, tais como o saber ler, escrever e contar.

A contradição se configura pelo fato de o caráter do acesso que é dado aos conhecimentos desta natureza, para os trabalhadores, não ser pleno, como o que é proporcionado aos filhos da burguesia. Como já visto, a escola pública era para todos, mas não do mesmo tipo para todos. A dualidade educacional aparece como a real estrutura e fundamento da defesa da "escola pública".

Isto se deve, fundamentalmente, ao tipo novo de relações de produção que passou a se construir. Se é certo que as revoluções burguesas promoveram a emancipação política dos servos, por outro lado, a sua emancipação humana foi obliterada, pois manteve-se a dependência econômica dos trabalhadores, do proletariado, transformados nos "novos servos" - antes, do senhor feudal; agora, "servos" dos capitalistas.

Com efeito, o regime burguês emancipou os homens das relações de dependência pessoal, vigentes na feudalidade; mas a liberdade política, ela mesma essencial, esbarrou sempre num limite absoluto, que é próprio do regime burguês: nele, a igualdade jurídica (todos são iguais perante a lei) nunca pode se traduzir em igualdade econômicosocial - e, sem esta, a emancipação humana é impossível. (NETTO e BRAZ, 2010, p. 19).

Todavia, nem todas as contradições são negativas para os trabalhadores. No campo educacional/cultural, apesar de todo o desinteresse das classes economicamente dirigentes em dar acesso efetivo aos trabalhadores quanto aos conhecimentos sistematizados e teóricos, mediados pela escola, percebe-se o potencial da escolarização como mediação necessária para a elevação do nível cultural das classes exploradas e da importância da escola no processo de luta rumo à emancipação humana omnilateral da classe trabalhadora.

O "capital" também percebe isto e procura limitar, tanto quanto possível, o acesso das classes subalternas aos conhecimentos "escolares" em "doses homeopáticas": somente aquele mínimo de conhecimentos que interessam para o bom funcionamento do sistema econômico, político e social estabelecidos. 
Mas, conforme já mencionado, como é difícil fixar este limite, a classe explorada tem aí um campo de luta contra a classe exploradora e se devidamente aproveitado, a escola pode se converter em mediação contra-hegemônica a favor dos subalternos.

\section{Referências:}

ALVES, D. Intelectuais Coletivos e o Projeto Nacional de Educação para a Classe Trabalhadora forjado nas décadas de 1930 e 1940 no Brasil. In: Revista online Conversas e Pesquisas. Rio de Janeiro: UERJ; Linha de Pesquisa/CNPQ: Intelectuais e Educação no Mundo Ibero-americano, v.1, n.1, p. 157-187, dez. 2018. [ISSN: 2596-0083]. Disponível em: $<$ https://conversasepesquisas.files.wordpress.com/2019/01/conversas-e-pesquisas11-01-2019-espelhada.pdf>. Acesso em: 15.fev.2019.

CAMPELLO, A. Dualidade Educacional. In: PEREIRA, I; LIMA, J. Dicionário da educação profissional em saúde. Rio de Janeiro: EPSJV/FIOCRUZ, p. 136-141, 2009. Disponível em: <http://www.epsjv.fiocruz.br/publicacao/livro/dicionario-daeducacao-profissional-em-saude-segunda-edicao-revista-e-ampliada>. Acesso em: 15.mar.2019.

CIAVATTA, M. Trabalho como princípio educativo. In: PEREIRA, I; LIMA, J. Dicionário da educação profissional em saúde. Rio de Janeiro: EPSJV/FIOCRUZ, p. 408-415, 2009. Disponível em: <http://www.epsjv.fiocruz.br/publicacao/livro/dicionario-da-educacao-profissional-emsaude-segunda-edicao-revista-e-ampliada>. Acesso em: 16.abr.2019.

ENGELS, F. A origem da família, da propriedade privada e do Estado. $3^{\text {a }}$. ed. Rio de Janeiro: BestBolso, 2018. [Tradução: Leandro Konder; Aparecida Maria Abranches]

FRIGOTTO, G. A produtividade da escola improdutiva: um (re) exame das relações entre educação e estrutura econômico-social e capitalista. $6^{a}$. ed. São Paulo: Cortez, 2001.

GRAMSCI, A. Cadernos do cárcere. 2ª ${ }^{a}$ ed. Rio de Janeiro: Civilização Brasileira, 2001. 2 v.

MARX, K. O Capital: crítica da economia política. Rio de Janeiro: Civilização Brasileira, 2008. Livro I. 1 v.

MONASTA, A. Antônio Gramsci. Recife, PE: Editora Massangana; Fundação Joaquim Nabuco, 2010.2 Disponível em: $<$ http://www.dominiopublico.gov.br/download/texto/me4660.pdf>. Acesso em: 12.jun.2019.

NETTO, J; BRAZ, M. Economia política: uma introdução crítica. 6⿳亠丷. ed. São Paulo: Cortez, 2010. 
OLIVEIRA, L; PIRES, A. Da precarização do trabalho docente no Brasil e o processo de reestruturação produtiva. In: Revista do Direito Público. Londrina, PR, v.9, n.1, p.73-100, jan./abr. 2014. DOI: 10.5433/1980-511X.2014v9n1p73. Disponível em: <http://www.uel.br/revistas/uel/index.php/direitopub/article/view/17128/14324>.

Acesso em: 10.jun.2019.

SAVIANI, D. Escola: Dominação ou Transformação? In: Painel sobre educação - VI Congresso da APP-Sindicato. Foz do Iguaçu, PR: APP-Sindicato, 26 de outubro de 1995. CD-ROM. Vídeo da Conferência.

SAVIANI, D. O trabalho como princípio educativo frente às novas tecnologias. In: FERRETTI, C. [et all]. Novas tecnologias, trabalho e educação: um debate multidisciplinar. Petrópolis, RJ: Vozes, 1994. Disponível em: $<$ https://www.ufpr.cleveron.com.br/arquivos/EP_104/dermeval_saviani.pdf>. Acesso em: 20.abr.2019.

SAVIANI, D. Trabalho e educação: fundamentos ontológicos e históricos. In: Revista Brasileira de Educação. Campinas, SP: Autores Associados, v. 12, n. 34, jan./abr. 2007. Disponível em: <http://www.scielo.br/pdf/rbedu/v12n34/a12v1234.pdf>. Acesso em: 20.abr.2019.

SINGER, P. O capitalismo: sua evolução, sua lógica e sua dinâmica. São Paulo: Moderna, 1987.

ZANELLA, J. 0 trabalho como princípio educativo do ensino. Tese (Doutorado em Educação). Campinas: UNICAMP; Faculdade de Educação, 2003. Disponível em:<http://repositorio.unicamp.br/bitstream/REPOSIP/252569/1/Zanella_JoseLuiz_D .pdf>. Acesso em: 15.mar.2019. 